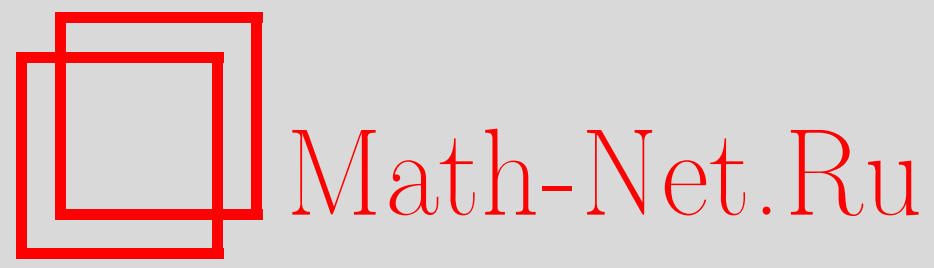

М. К. Валюженич, А. Л. Кривченко, П. А. Никульшин, Получение покрытий на основе титана путем синтеза тугоплавких соединений, Вестн. Сам. гос. техн. ун-та. Сер. Физ.-мат. науки, 2004, выпуск 27, 103-106

DOI: https://doi.org/10.14498/vsgtu283

Использование Общероссийского математического портала Math-Net.Ru подразумевает, что вы прочитали и согласны с пользовательским соглашением

http: //www.mathnet.ru/rus/agreement

Параметры загрузки:

IP : 3.81 .55 .215

26 апреля 2023 г., 14:24:05 
Построенные модели наглядно показали, что в $\gamma \rightarrow \alpha$ превращении возрастание роли диффузионных процессов сопровождается увеличением дробности в строении образующихся фаз.

БИБЛИОГРАФИЧЕСКИЙ СПИСОК:

1. Barakhtin B.K., Semicheva T.G., Vysotsky V.M. Morphology of interface boundaries and low-carbon cold resistant steel strength at variation of cooling conditions during thermomechanical treatment // Eurastrencold-2002. Труды 1 Евразийского симпозиума по проблемам прочности материалов и машин для регионов холодного климата. Якутск: ИПС СО РАН, 2002. Т.2. С. 3-10.

2. Встовский Г.В., Колмаков А.Г., Бунин И.Ж. Введение в мультифрактальную параметризацию структур материалов. Москва-Ижевск: НИЦ Регулярная и хаотическая динамика, 2001. 116 с.

3. Божокин С.В., Паршин Д.А. Фракталы и мультифракталы. Ижевск: НИЦ Регулярная и хаотическая динамика, 2001. $126 \mathrm{c}$.

4. Барахтин Б.К. Новые возможности материалографии // Вопросы материаловедения. 1995. № 1. С.154-156.

5. Барахтин Б.К., Чашников В.Ф. Программа ЭВМ для мультифрактального анализа изображений структур металлов и сплавов // Вопросы материаловедения. 2001. № 4(28). С. 5-8.

6. Чернявский К.С. Стереология в металловедении. М.:Металлургия, 1977. 280 с.

7. Барахтин Б.К., Зворыгин Р.Г. Условия получения надежных результатов при мультифрактальном анализе изображений изломов и структур материалов // Цифровая микроскопия. Материалы школы-семинара. Екатеринбург: УГТУ-УПИ, 2002. С. 59-64.

8. Газале М. Гномон. От фараонов до фракталов. Москва - Ижевск: Институт компьютерных исследований, 2002. $272 \mathrm{c}$.

Работа выполнена при поддержке гранта Президента России (гр. № НШ-1505.2003.8).

УДК 621.785. 5

М. К. Валюжсенич, А. Л. Кривченко, П. А. Никульшин

\section{ПОЛУЧЕНИЕ ПОКРЫТИЙ НА ОСНОВЕ ТИТАНА ПУТЕМ СИНТЕЗА ТУГОПЛАВКИХ СОЕДИНЕНИЙ}

Изучены возможности получения боридных покрытий на основе титана ВТ9 и ОТ4. Используя рентгеноструктурный анализ и другие физико-механические методы исследования, были выявлены возможности и закономерности образования тугоплавких соединений.

В последнее время в промышленную технологию создания упрочняющих и защитных покрытий успешно внедряются импульсные детонационные методы обработки поверхности, которые позволяют получать покрытия, избегая при этом непосредственного нагрева обрабатываемого изделия.

Формирование тугоплавких покрытий на металлах и сплавах требуют в большинстве случаев наличия высоких температур (выше 1000К), необходимых либо для образования самого соединения, либо для создания прочной связи между покрытием и основой. Это обстоятельство в значительной степени тормозит создания покрытия из тугоплавких соединений, так как нагрев до высоких температур приводит к нежелательным физико-химическим и структурным изменениям основы изделия.

Перспективным направлением создания покрытий из тугоплавких соединений является метод взрывоплазменного напыления, который основан на воздействии мощных импульсных потоков низкотемпературной плазмы на обрабатываемую поверхность и распыляемый порошок.

Целью настоящей работы явилось изучение возможностей взаимодействия материала подложки с активным элементом газового потока. В качестве основы служили образцы из титановых сплавов ВТ9 и ОТ4, а активным элементом служил порошкообразный бор. Выбор такой системы основан на физико-механических свойствах возможных продуктов реакции, а также термодинамических характеристик данных элементов.

В общем случае, при взаимодействии высокотемпературного газового потока с поверхностью титановых образцов в присутствии порошка бора, образуется монолитное покрытие.

На рис. 1 показана рентгенограмма с поверхности покрытия исследуемых образцов. 


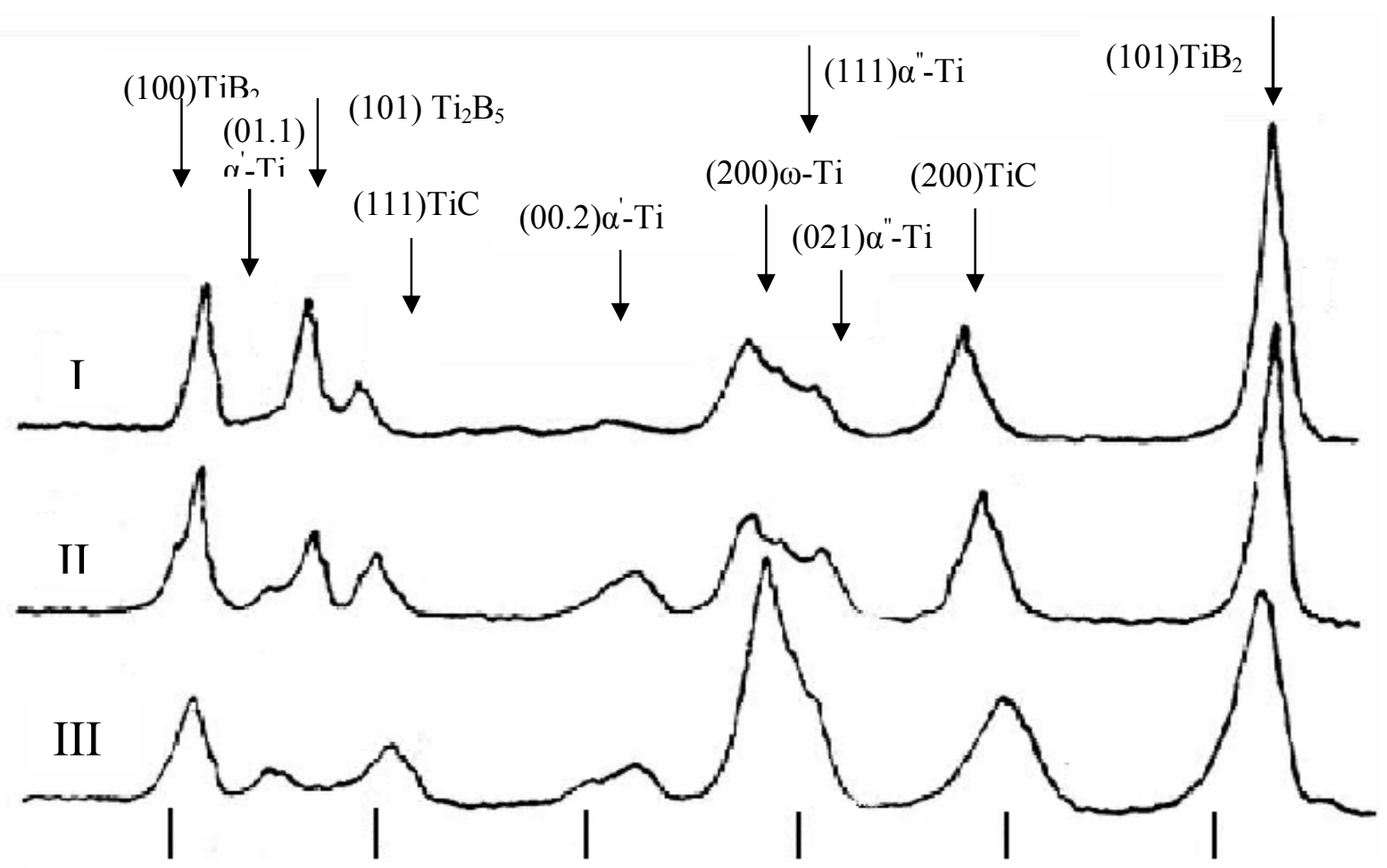

Р и с. 1. Рентгенограмма с поверхности покрытия образцов.

Вульф-брэгговский угол, град:

$\mathrm{I}-q=4,7 * 10^{8} \mathrm{BT} / \mathrm{M}^{2} ; \mathrm{II}-q=3 * 10^{8} ; \mathrm{BT} / \mathrm{M}^{2} ; \mathrm{III}-q=1,2 * 10^{8} \mathrm{BT} / \mathrm{M}^{2}$

Рентгенографический анализ показал, что основным компонентом покрытия является диборид титана и свободный (остаточный) титан. Их содержание в покрытии зависит от величины плотности теплового потока. Фазовый состав остаточного титана представлен $\alpha^{\prime}, \omega$ и $\alpha^{\prime \prime}$ фазами титана. В сплаве ВТ-9 $\omega$ фаза составляет основу остаточного титана (от 60 до 90\%). В сплаве ОТ4 ее содержание невелико и, в основном, преобладают $\alpha^{\prime}$ и $\alpha^{\prime \prime}$ - фазы. Кроме этого в покрытии присутствует незначительное (до 10\%) количество карбида титана нестехиометрического состава. Его образование, вероятно, обусловлено погрешностями эксперимента. С изменение плотности теплового потока содержание карбида титана в составе покрытия остается практически постоянным.

На рис. 2 показана зависимость толщины покрытия от плотности теплового потока.

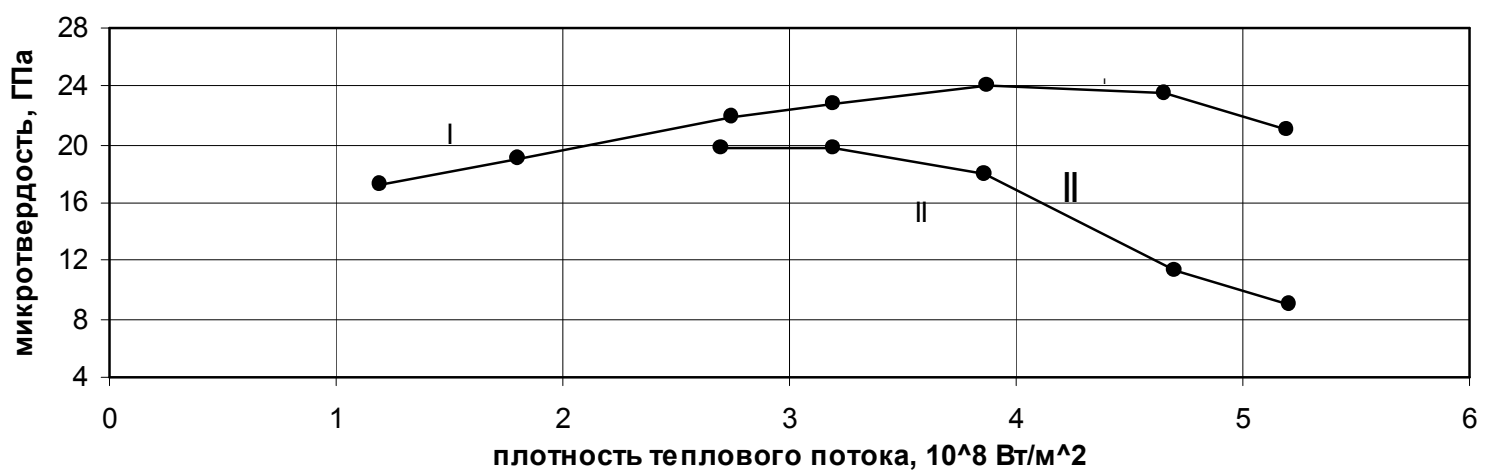

Р и с. 2. Зависимость толщины покрытия от плотности теплового потока:

I- на поверхности покрытия; II - у границы с основной

Из графика зависимости видно, что с ростом теплового потока непрерывно повышается величина микротвердости покрытия и достигает максимума (24-26 ГПа) при значениях $\mathrm{q}=(3,5 \div 4) 10^{8} \mathrm{BT} / \mathrm{m}^{2}$. Очевидно, что причиной роста твердости покрытия является повышение в его составе диборида титана. При дальнейшем увеличении плотности теплового потока следует 
незначительный спад микротвердости поверхностного слоя покрытия (кривая 1). Измерения микротвердости покрытия, проведенные вблизи границы раздела покрытия с основой, обнаруживают довольно резкий спад значений микротвердости при плотности теплового потока $\mathrm{q}=3,5 \cdot 10^{8} \mathrm{BT} / \mathrm{M}^{2}$ (кривая II).

На рис. 3 приведена зависимость изменения микротвердости по глубине покрытия.

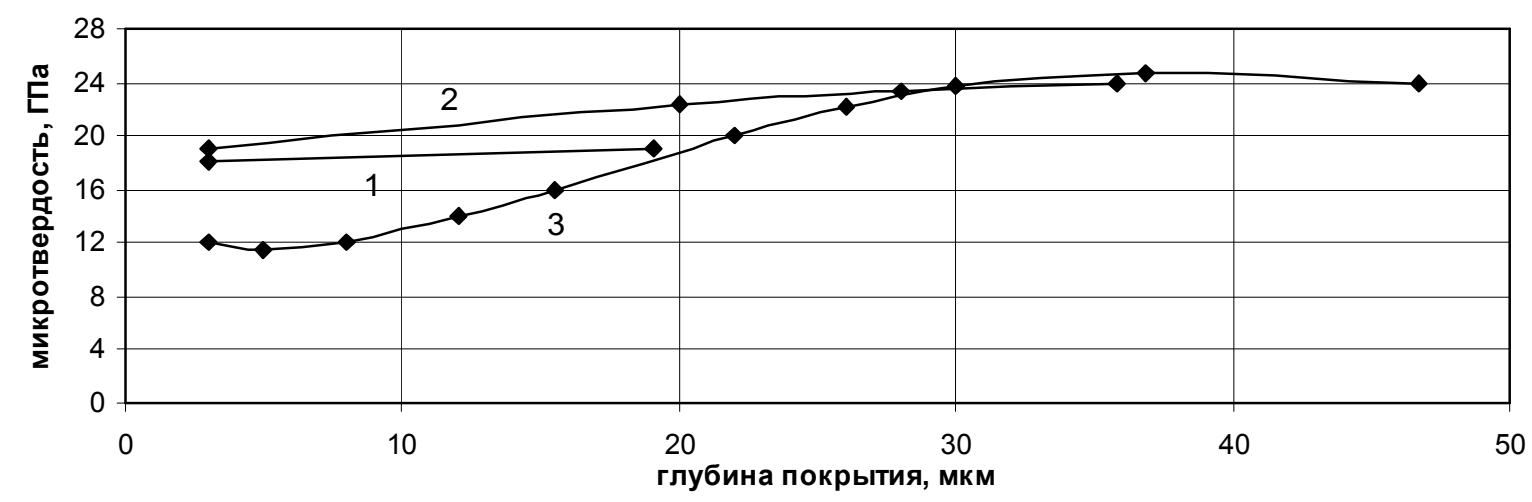

Р и с. 3. Изменение микротвердости по глубине покрытия: $1-q=2 \cdot 10^{8} \mathrm{BT} / \mathrm{m}^{2} ; 2-q=3,2 \cdot 10^{8} \mathrm{BT} / \mathrm{m}^{2} ; 3-q=4,7 \cdot 10^{8} \mathrm{BT} / \mathrm{m}^{2}$

Результаты измерения микротвердости по глубине покрытия показывают, что между слоем тугоплавкого соединения и основой имеется четкая граница. Равномерное распределение микротвердости по глубине покрытия, получаемого при плотности теплового потока $\mathrm{q}=2 \cdot 10^{8} \mathrm{BT} / \mathrm{m}^{2}$ (кривая 1) можно было бы считать результатом интенсивного диффузионного переноса конечного продукта реакции - $\mathrm{TiB}_{2}$ из поверхностных слоев покрытия к границе раздела с основой. Поскольку диффузия является термически активируемым процессом, то с ростом плотности теплового потока следовало бы ожидать, как и при $q=2 \cdot 10^{8} \mathrm{BT} / \mathrm{M}^{2}$ равномерного распределения микротвердости по глубине покрытия. Однако приведенные на рис. 3 зависимости свидетельствуют о том, что диффузионные процессы в данных условиях не могут обеспечить переноса конечного продукта синтеза на всю глубину образующегося покрытия и, вероятно, синтез $\mathrm{TiB}_{2}$ проходит по всей глубине покрытия, т. е. носит объемный характер.

На рис. 4 представлена зависимость толщины образующегося покрытия от величины плотности теплового потока.

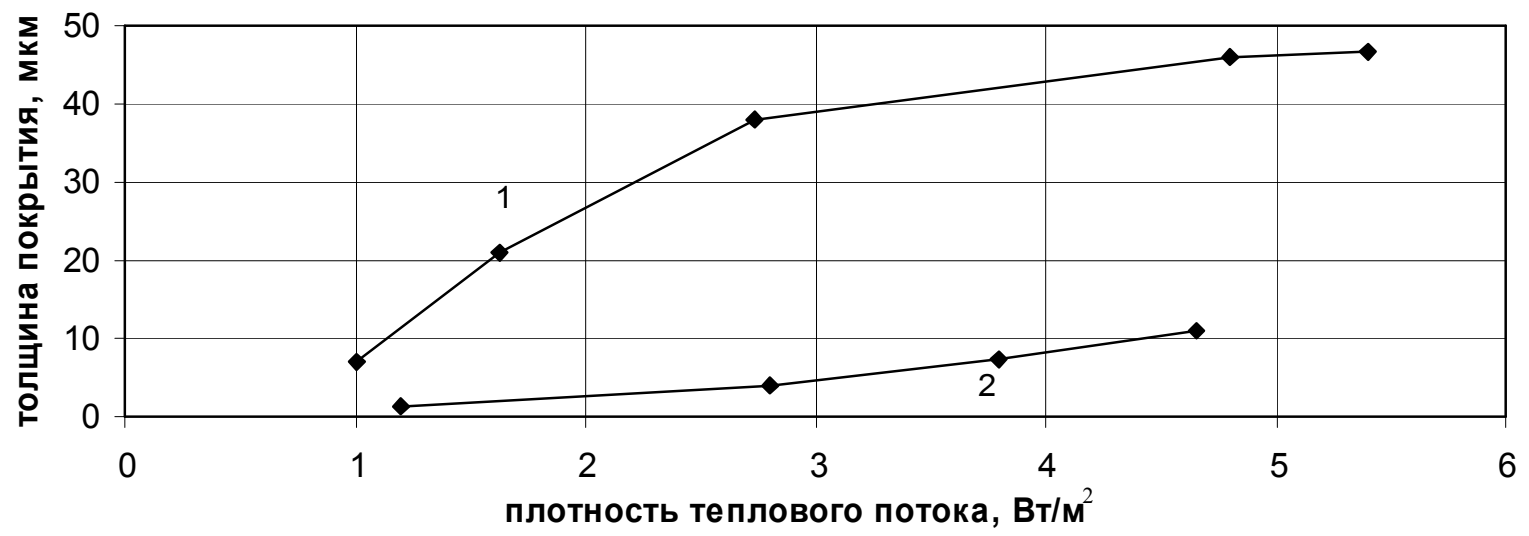

Р и с. 4. Зависимость толщины покрытия от плотности теплового потока: 1 - масса бора, равная 0,0004 кг; 2 - без порошка бора

Масса навески порошка бора с диаметром частиц, приблизительно равным 6 мкм, составляла $4 * 10^{-4}$ кг. Кривая 2 есть зависимость толщины слоя поверхностного расплава, полученного при обработке потоком ударно-сжатого аргона образцов ВТ9, от величины плотности теплового потока без порошка бора. Эксперименты по обработке сплава нейтральным потоком были проведены с целью выяснения механизмов формирования покрытия. 
Таким образом, в результате проделанной работы были изучены механизмы формирования тугоплавких покрытий с применением взрывоплазменного напыления. Приведенные анализы позволяют надеяться на перспективность использования полученных покрытий. Работа представляет интерес не только для формирования тугоплавких покрытий на металлах и сплавах, но и для физики прочности и пластичности твердых тел.

\section{БИБЛИОГРАФИЧЕСКИЙ СПИСОК}

1. Боровинская И. П., Мержанов А. Г. Самораспространяющийся высокотемпературный синтез тугоплавких неорганических соединений // Металлотермические процессы в химии и металлургии. Новосибирск: Наука, 1971. С. $58-65$

2. Анисимов С. И. Действие излучений большой мощности на металлы. М: Наука, 1970. 269с.

3. Бекренев А. Н. Последеформационные процессы высокоскоростного нагружения. М.: Металлургия, 1992.340 с.

4. Защитные покрытия. Труды 8-го Всесоюзного совещания по жаростойким покрытиям. М.: АНСССР, 1979.

5. Валюженич М. К., Кириленко Ю. Н., Кривченко А. И. Получение боридных покрытий на титановых сплавах с помощью ударно-сжатой плазмы // Температуроустойчивые функциональные покрытия. Сборник трудов XVIII совещания. Тула. 2001. С. 59-60.

\section{УДК 539.2}

\section{Л.С. Васильев}

\section{МЕХАНИЗМ ЗАРОЖДЕНИЯ ПОР И МИКРОТРЕЩИН ВБЛИЗИ ДИСЛОКАЦИОННЫХ СКОПЛЕНИЙ}

Рассмотрен процесс зарождения и развития микропор и микротрещзин вблизи стопоров скоплений краевых дислокаџий с позиций термофлуктаџионной теории прочности. Показано, что в стадии зарождения несплошностей вещество испытывает ряд фазовых превращений - локальное плавление, кавитацию расплава, сублимачию твердой фазы. На стадии развития микропор и микротрещуин определяющими эффектами являются сублимация и ползучесть твердой фазыл.

Введение. Проблема зарождения пор и микротрещин в металлах и сплавах является одной из центральных в теории прочности [1]. Существующие в настоящее время модели и схемы, предложенные в разное время Зинером, Стро, Котреллом и т.д. [1] слишком грубы и феноменологичны и не могут объяснить начальный процесс возникновения полостей в сплошном теле на атомарном уровне. В большинстве таких теорий просто предполагается, что зародышевая полость возникает как-то сама собой при выполнении некоторых энергетических или силовых условий [1]. При этом часто упускается из вида тот факт, что размеры и форма минимальных зародышевых полостей могут существенным образом зависеть от общих условий устойчивости и равновесия термодинамической системы $[2,3]$. Физически это следует из того, что с позиций термофлуктуационной теории прочности [4] возникновению минимальной зародышевой полости должны предшествовать процессы накопления повреждений структуры тела, проявляющиеся в виде локальных разрывов атомных связей. В металлах и сплавах этому соответствует появление неравновесных вакансий и их комплексов. При растягивающих нагрузках эти комплексы могут термофлуктуационным путем образовывать минимальные зародышевые полости, которые дают возможность для роста пор и трещин микроскопических размеров. Ясно, что не все вакансионные комплексы способны к росту, а лишь те из них, которые соответствуют условиям термодинамической устойчивости [5].

Описанный процесс имеет свои особенности вблизи скопления дислокаций. Оказывается, что образование зародышевой полости кинетически выгодно, если оно реализуется через механизм локального плавления материала с последующей кавитацией расплава.

Механизм локального плавления. К моменту исчерпания запаса пластичности при пластическом деформировании устанавливается самый высокий уровень упрочнения материала, равный пределу прочности $\sigma_{B}$. Для сталей это составляет $(5 \div 15) \cdot 10^{8}$ Па. Одновременно с этим в материале возникает большое количество застопоренных коротких скоплений, состоящих обычно из $10 \div 30$, и дислокаций. Стопорами могут служить выделения сторонних фаз, границы и субграницы поликристаллов и т.п. [1,4]. В качестве характерного примера для проведения расчетов в работе выбрано плоское скопление из 30-и краевых дислокаций, застопоренное выделением инородной фазы (см. рис1.). 